\title{
The Dose-dependent Effect of an 830-nm, 450-mW Low-Level Laser Therapy on the Myofacial Trigger Point of the Upper Trapezius Muscle: A Randomized, Double-Blinded, Clinical Trial
}

\author{
Jung Hoon LeE, MS, PT ${ }^{1)}$, Jin TAE Han, PhD, $\mathrm{PT}^{2)}$ \\ ${ }^{1)}$ Department of Physical Therapy, Inje University Pusan Paik Hospital \\ ${ }^{2}$ Department of Physical Therapy, College of Science, Kyungsung University: \\ 309 Suyeong-ro, Nam-gu, Busan, 608-736, Republic of Korea. \\ TEL: +82 51-663-4871,FAX: +82 51-623-4873,E-mail: jthan2001@ks.ac.kr
}

\begin{abstract}
Purpose] The purpose of this study was to evaluate the dose-dependent effect of treatment with an 830$\mathrm{nm}, 450-\mathrm{mW}$ GaAlAs laser on changes of the pressure-pain threshold (PPT) of the myofascial trigger point (MTrP) of the upper trapezius (UT) muscles of seated workers, in comparison with a placebo GaAlAs laser. [Subjects] Twenty-four seated workers (10 males, 14 females) with UT pain agreed to participate in this study. [Methods] The subjects were given treatment either with a placebo GaAlAs laser or an active GaAlAs laser according to a doubleblinded, randomized procedure. [Results] The placebo group did not show significant changes in PPT after 1 min, 2 min and 5 min of low-level laser therapy (LLLT). The active group did not show significant changes in pressurepain threshold (PPT) after $1 \mathrm{~min}$ and 2 min of LLLT. However, significant changes in PPT were apparent after 5 min of LLLT. [Conclusion] We suggest that a higher energy, such as $1929 \mathrm{~J} / \mathrm{cm}^{2}$, may be necessary to produce an immediate effect on PPT when treating the MTrP of the UT with an 830-nm, 450-mW GaAlAs laser.

Key words: GaAlAs laser, Pressure-pain threshold, Seated worker
\end{abstract}

(This article was submitted Jul. 12, 2011, and was accepted Aug. 4, 2011)

\section{INTRODUCTION}

Fifty-seven percent of office workers complain of neck and shoulder pain ${ }^{1)}$. Due to static contractions in a continuous sitting position, ischemia in the trapezius muscle and an increase of intramuscular tissue pressure result in stiffness, dullness, pain and increase in muscle hardness ${ }^{2}$. However, drugs and exercises to treat the musculoskeletal problems of office workers have not been always useful ${ }^{3)}$.

Low-level laser therapy (LLLT) is the irradiation of light within the output range of $1-500-\mathrm{mW}$ and wavelength of $600 \sim 1000 \mathrm{~nm}^{4)}$. In a clinical setting, LLLT has been reported to be effective in pain control of musculoskeletal disorders $^{5)}$ and the reduction of drug usage ${ }^{6,7)}$. However, some studies propose that there are no beneficial effects of LLLT in musculoskeletal pain control ${ }^{8,9)}$. This may be explained by the incorrect application and dosage of LLLT $^{10)}$. The clinical efficiency of LLLT remains controversial and additional studies about the optimum dosage for immediate effect on musculoskeletal pain control using LLLT with a wavelength of $830 \mathrm{~nm}$ and a 450-mW output are required.

The purpose of this study was to evaluate the dosedependent effect of an 830-nm, 450-mW GaAlAs laser on the pressure-pain threshold (PPT) changes of the myofascial trigger point (MTrP) of the upper trapezius (UP) muscle of seated workers, in comparison with a placebo GaAlAs laser.

\section{SUBJECTS AND METHODS}

The subjects of this study were 10 males [age: $25.4 \pm 1.6$ years (mean $\pm \mathrm{SD}$ ); height: $174.2 \pm 5.2 \mathrm{~cm}$; body weight: $66.4 \pm 4.0 \mathrm{~kg}$ ] and 14 females [age: $23.7 \pm 3.2$ years (mean \pm SD); height: $161.7 \pm 6.0 \mathrm{~cm}$; body weight: $50.5 \pm 4.6 \mathrm{~kg}$ ] who were seated workers with pain of the UP. Subjects were selected in a screening process to prove the presence of MTrP in the UP by a physical therapist with 10 years of palpation experience. Inclusion criteria of this study were: suffering from pain in the UP for more than 6 months, and a PPT level of UP below $3 \mathrm{~kg}$. Exclusion criteria of this study were: a history of fracture of the shoulder joint or the cervical spine; a history of heart disease, pacemaker use, psychological disorders, or epilepsy; and pregnancy or use of therapeutics such as drugs and/or shoulder exercises. Prior to the start of the study, all subjects understood the purpose of this study and spontaneously signed consent forms, in accordance with the ethical standards of the Declaration of Helsinki. 
The subjects were given either active GaAlAs laser (SClaser CTLS-8; EINS MEDICAL, Busan, Korea: $830 \mathrm{~nm}$, $450 \mathrm{~mW}, 0.3 \mathrm{~cm}$ spot diameter, $0.07 \mathrm{~cm}^{2}$ spot size, 35.71 $\mathrm{W} / \mathrm{cm}^{2}$ ) or a placebo GaAlAs laser treatment according to a double-blinded and randomized procedure. The laser treatment parameters are shown in Table 1.

The randomization procedure of the LLLT was carried out using simple cards, A (active LLLT) or B (placebo LLLT), which subjects received from an observer who was not participating in the study. The simple cards selected were delivered to a physical therapist who operated the laser in the active or placebo mode. Both the subjects and the investigator were blind to the type of LLLT mode. The laser probe was placed on the skin contact angle of $90^{\circ}$ on the MTrP in the dominant UT during LLLT administration. LLLT were administered at intervals of one week for $1 \mathrm{~min}$, $2 \mathrm{~min}$, and $5 \mathrm{~min}$, respectively, to eliminate the carryover effect of LLLT. Both subjects and the laser operator put on protective goggles to protect their eyes and for protection from blindness during the LLLT.

The PPT of the subjects was evaluated using an algometer (Pain Test-Model FPK; Wagner Instruments, Greenwich, CT) before and after the LLLT in a relaxed sitting position by the same investigator. The algometer is a clinically used instrument with a high reliability of assessment of tenderness ${ }^{11,12)}$. The algometer increased pressure by $0.1 \mathrm{~kg}$ per second on the MTrP of subject's dominant UT until they indicated that the pressure had become painful ${ }^{13)}$.

Statistical analysis was performed using the SPSS statistical package (version 14.0, SPSS, Chicago, IL, USA). Repeated one-way ANOVA was used for the active and placebo groups to analyze changes in PPT and MTrP of the UP. The comparative analysis was post-hoc tested by the Bonferroni's correction. The statistical significance level used in the analysis was $\mathrm{p}<0.05$.

\section{RESULTS}

The PPT of placebo and active groups are shown in Table 2. The placebo group did not show significant changes in PPT after $1 \mathrm{~min}, 2 \mathrm{~min}$ and 5 min of LLLT $(p>0.05)$. The active group did not show significant changes

Table 1. Laser parameters used in this study

\begin{tabular}{cccc}
\hline \multirow{2}{*}{ Laser parameters } & \multicolumn{3}{c}{ Treatment time } \\
\cline { 2 - 4 } & 1 min & 2 min & 5 min \\
\hline Energy $(\mathrm{J})$ & 27 & 54 & 135 \\
Energy density $\left(\mathrm{J} / \mathrm{cm}^{2}\right)$ & 386 & 771 & 1,929 \\
\hline
\end{tabular}

in PPT after $1 \mathrm{~min}$ and 2 min of LLLT ( $>00.05$ ). However, a significant change in PPT was seen after 5 min of LLLT $(\mathrm{p}<0.05)$.

\section{DISCUSSION}

In this study, we failed to find differences between the active and placebo groups after $1 \mathrm{~min}$ and 2 min of LLLT (830 nm, $450 \mathrm{~mW}$, GaAlAs laser) in PPT of the MTrP of the UT. However significant changes were seen in PPT after 5 min of LLLT in the active group. LLLT has been used for noninvasive physical therapy in the treatment of musculoskeletal disorders since it induces photochemical and photobiological effects in cells and tissues which increase the natural healing process rather than having a thermal effect ${ }^{14)}$. LLLT has been suggested to improve cellular respiration in MTrPs by regulating microcirculation ${ }^{15)}$ and to provide analgesia by increasing adenosine triphosphate production related with cell level changes ${ }^{15,16)}$. To produce these effects, the parameters such as wavelength, power density, output frequency, energy density and duration of LLLT are varied ${ }^{15,17)}$.

Energy density seems to be the most important parameter ${ }^{15)}$. Tunér and Hode ${ }^{14)}$ proposed that an energy density of $4-10 \mathrm{~J} / \mathrm{cm}^{2}$ is necessary for deep region pain treatment using a GaAlAs laser. However, this energy density was not necessary for an immediate PPT change. Although high dosages such as $386 \mathrm{~J} / \mathrm{cm}^{2}$ (1 $\mathrm{min}$ application) and $771 \mathrm{~J} / \mathrm{cm}^{2}$ (2 min application) were delivered in this study, there were no immediate effects. In addition, because the thickness of the subcutaneous layers and the UP was at least $1 \mathrm{~cm}^{18,19)}$, the dosage actually received in the painful area may have been diminished to one tenth of the ordinal intensity ${ }^{14)}$. However, the higher energy density of $1,929 \mathrm{~J} / \mathrm{cm}^{2}$ ( 5 min application) produced an immediate effect on PPT. These results suggest that a higher energy density may be necessary to produce an immediate effect on PPT when applying an 830-nm, 450$\mathrm{mW}$ GaAlAs laser to the MTrP of muscles more than $1 \mathrm{~cm}$ thick.

This study had a few limitations. First, it was difficult to detect differences between dosages due to the small sample size. Second, time slots such as $3 \mathrm{~min}$ and $4 \mathrm{~min}$ were not used. Third, the results of the $1 \mathrm{~min}$ and $2 \mathrm{~min}$ of LLLT do not necessarily mean that LLLT is not effective in reducing pain because the follow-up was too short-term. Fourth, pain scale beyond the PPT has not been evaluated. Further, longer follow-up studies with many patients with relatively large MTrPs are needed to find the optimum dosage for therapeutic efficacy of an 830-nm, 450-mW GaAlAs laser.

Table 2. Comparison of PPT of the upper trapezius muscle in the placebo group $(\mathrm{N}=12)$ and active group $(\mathrm{N}=12)$

\begin{tabular}{lcccc}
\hline \multirow{2}{*}{ Groups } & \multicolumn{4}{c}{ PPT $(\mathrm{kg}$, mean \pm SD) } \\
\cline { 2 - 5 } & Initial & $1 \mathrm{~min}$ & $2 \mathrm{~min}$ & $5 \mathrm{~min}$ \\
\hline Placebo LLLT & $0.95 \pm 0.42$ & $0.94 \pm 0.48$ & $1.20 \pm 0.51$ & $1.70 \pm 0.66$ \\
Active LLLT & $1.12 \pm 0.43$ & $0.99 \pm 0.38$ & $1.14 \pm 0.46$ & $2.14 \pm 0.64^{*}$ \\
\hline
\end{tabular}

${ }^{*} \mathrm{p}<0.05$, LLLT; Low level laser therapy, PPT; Pressure-Pain Threshold. 


\section{ACKNOWLEDGEMENT}

This research was supported by a Kyung-sung University Research Grant in 2010.

\section{REFERENCES}

1) Tola S, Riihimäki H, Videman T, et al.: Neck and shoulder symptoms among men in machine operating, dynamic physical work and sedentary work Scand J Work Environ Health, 1988, 14: 299-305.

2) Larsson SE, Cai H, Oberg PA: Microcirculation in the upper trapezius muscle during varying levels of static contraction, fatigue and recovery in healthy women - a study using percutaneous laser-doppler flowmetry and surface electromyography. Eur J Appl Physiol Occup Physiol, 1993, 66: 483-488.

3) Hadi M, Ali SV, Isa MZ, et al.: Low level laser therapy (LLLT) for chronic low back pain (LBP). Eur J Sci Res, 2009, 29: 76-81.

4) Huang YY, Chen AC, Carroll JD, et al.: Biphasic dose response in low level light therapy. Dose Response, 2009, 7: 358-383.

5) Chow RT, Heller GZ, Barnsley L: The effect of $300 \mathrm{~mW}, 830 \mathrm{~nm}$ laser on chronic neck pain: a double-blind, randomized, placebo-controlled study. Pain, 2006, 124: 201-210.

6) McNeely ML, Olivo SA, Magee DJ: A systematic review of the effectiveness of physical therapy interventions for temporomandibular disorders. Phys Ther, 2006, 86: 710-725.

7) Bjordal JM, Couppé C, Chow RT, et al.: A systematic review of low level laser therapy with location specific doses for pain from chronic joint disorders. Aust J Physiother, 2003, 49: 107-116.

8) Djavid GE, Mehrdad R, Ghasemi M, et al.: In chronic low back pain, low level laser therapy combined with exercise is more beneficial than exercise alone in the long term: a randomised trial. Aust J Physiother, 2007, 53: 155160.

9) Gam AN: The effect of low level laser therapy on musculoskeletal pain: a meta analysis. Pain, 1993, 52: 63-66.

10) Beckerman H, Bie RA, Bouter LM: The efficiacy of laser therapy for musculoskeletal and skin disorders: A criteria based meta-analysis of randomised clinicaly trials. Phys Ther, 1992, 72: 483-491.

11) Delaney GA, McKee AC: Inter and intra-rater reliability of the pressure threshold meter in measurement of myofascial trigger point sensitivity. Am J Phys Med Rehabil, 1993, 72: 136-139.

12) Reeves JL, Jaeger B, Graff-Radford SB: Reliability of the pressure algometer as a measure of myofascial trigger point sensitivity. Pain, 1986, 24: 313-321.

13) Hakgüder A, Birtane M, Gürcan S, et al.: Efficacy of low level laser therapy in myofascial pain syndrome: an algometric and thermographic evaluation. Lasers Surg Med, 2003, 33: 339-343.

14) Tunér J, Hode L: Laser therapy: clinical practice and scientific background. Prima Books, 2002.

15) Simunovic Z: Low level laser therapy with trigger points technique: A clinical study on 243 patients. J Clin Laser Med Surg, 1996, 14: 163-167.

16) Passarella S: He-Ne laser irradiation of isolated mitochondria. J Photochem Photobiol B, 1989, 3: 642-643.

17) Ay S, Doğan SK, Evcik D: Is low-level laser therapy effective in acute or chronic low back pain? Clin Rheumatol, 2010, 29: 905-910.

18) Cescon C, Rebecchi P, Merletti R: Effect of electrode array position and subcutaneous tissue thickness on conduction velocity estimation in upper trapezius muscle. J Electromyogr Kinesiol, 2008, 18: 628-636.

19) O'Sullivan C, Meaney J, Boyle G, et al.: The validity of Rehabilitative Ultrasound Imaging for measurement of trapezius muscle thickness. Man Ther, 2009, 14: 572-578. 